\title{
Research on Management Model Based on Deep Learning
}

\author{
Yuting Zhao \\ School of Economics and Management, Harbin University, Heilongjiang, Harbin 150086, China \\ Correspondence should be addressed to Yuting Zhao; zhaoyuting20191@163.com
}

Received 11 March 2021; Revised 15 April 2021; Accepted 23 April 2021; Published 21 August 2021

Academic Editor: M. Irfan Uddin

Copyright @ 2021 Yuting Zhao. This is an open access article distributed under the Creative Commons Attribution License, which permits unrestricted use, distribution, and reproduction in any medium, provided the original work is properly cited.

In this study, the focus was on the development of management models and future prediction for the cost and risk by using an improved deep learning (DL) algorithm. Management model can be defined as the management activities that are interlinked and organized inside organization of institutions. Different opportunities and different organizations are offered by different management models. Proper management models lead to strategies and decisions help to success organization. Deep neural network (DNN) is proposed to make good prediction for organization for increasing the cost and reduce risk in companies and institutions. The error of prediction is updated according to variable hidden layers and nodes within iteration. Improved DNN is used and modify weights that have an effect on the features extracted in advance to increase the accuracy and precisions are used. The proposed method is based on dynamic hidden layers with backpropagation and feedforward. Absolute mean relative error (AMRE) and variance $\left(R^{2}\right)$ are used for evaluation in term of accuracy. The training system is used with three available datasets from big company, health issue, and industry. Gained result proves the worth of the proposed system and is suitable for predicting complex data and reducing the risk as possible.

\section{Introduction}

Management model can be defined as the choices by top executives' company in terms of defining motivate effort, allocating resources, defining objectives, and coordinating activities. Another side of management is how to identify the management work. There are four key steps for management model which are rational goal, internal process, open system, and human relation [1].

Management models consist of several concepts, and the main concept is successful decision-making based on successful criteria dependent on conclusions according to expected results. First idea of the management model comes from more than hundred years ago, where people established administrative groupings by organizing specific groups in the form of small groups [2]. Then, the consulting firms developed management models that differ from one to another and then promoted them. In this study, we start with brief excursion of history and then pay attention to explore some management models. There are four management models which describe the time importantly, as well as the description of the digital area such equal importance. The four interested models of management are illustrated in Figure 1. These models do not intersect with each other, but work as a complement to each other.

In practice, the previously used management models are considered successful to some extent but need to be developed to be acceptable today. This actually is not always an appropriate thing [3].

\section{Management Classical Style Approach}

There are two classical style approaches:

(1) Scientific management

(2) Administrative management

Scientific management: this application uses scientific method for increasing individual productivity of the workers. Typically, manager or leader decides to use this type of management according to the previous experience of people managing. This type has advantages in addition to limitations, depending strongly on the experience and learning from past training [4]. 
Administrative management considers principles of management for effective structure in addition to management of the organization (organizing, coordinating, planning, commending, and controlling). They are the main principles that are used to manage and structure the organization. This determines the low level of management and controls the skills.

\section{Human Relation Approach of Management}

According to managerial belief practice, productivity and morale which are strongly considered properly working to enhance the environment of worker capability. This style of management is easily recognizable because it relies on psychology, sociology, and individual understanding of real behavior, as well as group behavior. Therefore, education in such a group fits here as well as is well suited to co-administration. In the human relations approach, management often does not know that it is subordinate to human relations, but it is not [5].

\section{System Approach to Management}

It is expensive and complicated at the same time, and it satisfies the combination of human relation approach and classical approach [6].

Philosophy of system approach are

(i) Whole is better than the sum of parts (in the context of leading people/managing that pull of human relation and classical approach)

(ii) Related the sub and part system with each other in addition to whole

(iii) Close relation between environment and organization should be emphasised

(iv) Predicted pattern must be examined in terms of effectiveness

\section{Contingency Approach to Management}

Internal and external environments are considered in this approach. Its aim is to manage far from traditional theory such as $x$ and $y$, and its focus is on the fact when deciding or determining of practical management has to consider task nature and person nature [7].

Philosophy of this approach are

(i) Emphasis on there is no best way for managing people

(ii) Different situations need different managing approaches and methods

(iii) Before deciding the action, we need to focus on knowledge and theory organization

\section{Strategies of Management Model}

There are four essential strategies designed to be a set: setting objective (planning), coordinate activities, motivation, and decision-making. The activities of four groups must be executed in different ways for different organizations. In the objective case, we create boundaries according to short-time goals for long-term objective. In the motivation case, we define extrinsic motivation on one side and intrinsic motivation on another side. The management process that takes place in a formal and administrative form takes some time, and it is wise to take it into consideration, as shown in Figure 2.

Planning model works with short time strategy objective, extrinsic motivation, and strict decision-making strategy. When quest model defines the objective clearly, the management model takes the responsibility of making decision. In intrinsic, the employee can be decided and clearly defined, as well as objective and motivation can be decided [8].

For the discovery model, managerial process, motivation, decision-making, and objective are loose. The planning model is to mature operating the business for stable environment. The quest model is useful when establishing company in market competitive. The scientific model is considered for knowledge innovative organization. The discovery model is recommended in start with highly changing environment.

The management model can be use DL technique to make both prediction and designing. Management that makes decisions include a $70 \%$ chance of risk due to prediction as in project management [9]. DNN is used in this study as one of the DL techniques. Neural network consists of three main parts [10], which are input layer, hidden layer, and output layer; DNN is used here to predict the decision, as shown in Figure 3.

This manuscript is organized as follows: first the introduction, which gives a preliminary idea, and then a special section on previous studies related to the research, in addition to a section related to deep learning and its techniques, then the proposed method of work, and finally results and conclusions.

\section{Related Work}

In this section, literature review will be discussed in terms of the management model and evaluation of the management model. The management model is organizational ideology and paradigm. It is the way how the manager will manage the organization [11]. The management models create the advantage: when designed properly, a poor selection of the management model will limit the organization [12]. The organization limits in the operational and business model in terms of management [13]. The new management model was developed by defining six areas of activities which are technical financial, commerce, accountancy, security, and administrative [1, 14]. Different approaches are adopted by [15] on the management model in the army field that creates a concept of rational bureaucracy and focuses on the behavior of the leader according to rules of calculable. Decision analysis is used to predict the management model by using limits' condition in the water resources' model to understand the management of resources [16]. 


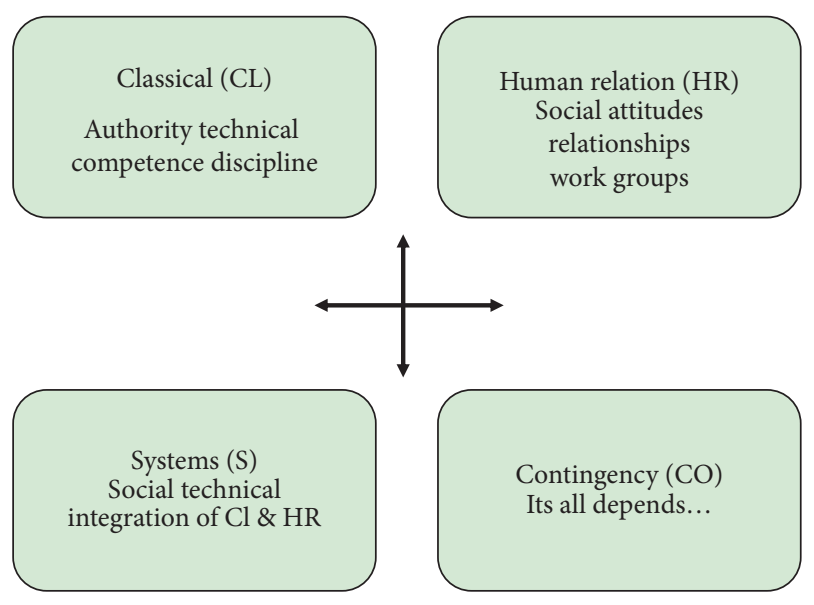

FIgURE 1: Main models of management.

DL is used in dynamic management of the detection model and establishes the policies in making decision, and time measurement is considered within the $5 \mathrm{G}$ model [17]. Many applications used DL in management especially in health management which is a critical approach that has an effect on design prediction in real time [18]. Reducing risk management in decision for pattern recognition using DL in [19] such system is used to improve the operation and solve congestion as well. Intelligent application used DL for the management model by processing services in Internet of Things (IoT) and edge computing as well $[20,21]$.

7.1. Application of DNN in Management Model. There are many different families of DNN at present used in the management model as a whole. This variety actually makes the evaluation very difficult; according to the standard reported scheme, we cannot list many of them but will present the most important one that is used in the management model. We try to cover these scopes that relate DL with the management model such as marketing, manufacturing, finance, and strategic management.

7.1.1. In Field of Marketing. DNN can be used and applied to many decisions of marketing, marketing before using statistical analysis to solve problem in prediction, typical issue of market segmentation or market dominantly modeling, classification of the pattern, identification of characteristics, target marketing, and sale forecasting. DNN approach when compared with the traditional method includes classification task and market response estimation. The problem with marketing is the lack of individual data of application. In this type, sales area needs good prediction of using DNN [22].

7.1.2. In Field of Finance. Many modeling and forecasting issues are frequently handled by DNN; the idea of using computer algorithm is to reduce the risk and increase probability of growth of money when dealing in different fields. Advantage of this type is to solve any nonlinear function and complexity of time series by NN that proved its worth in this model. Prediction of further data and pattern recognition: it is suitable to fit with complex calculation, and problem needs guaranty of the number of processing samples [23].

7.1.3. In the Field of Manufacturing. Prediction cost and time date scheduling are the main things needed to recover by DNN in addition to quality control and optimization. Forecasting data are required to ensure the quality of the product. Mange path of the product also needs good prediction in terms of cost and time consumption [24].

7.1.4. In Field of Strategic Managements. Main issues here are empirical research and strategy of planning performance, making decision controlled by Role to achieve better strategy under certain conditions. [25]. DNN is an efficient tool for clarifying and determining the relation between performance and planning of strategy, as well as making decision.

In this regard, we can notice that DNN approaches are different from other traditional methods and can achieve, by them, better results in many developer applications. Many reasons make it easy to use DNN, such as in case of data multivariate, when data are noisy or incomplete, and when data need high computational complexity.

7.2. Why Deep Neural Network. Many advantages allow us to choose DNN, and there are many reasons which are listed as follows:

(i) DNN models provide high accuracy with the result when comparing with other methods such as regression

(ii) Because deep learning is considered part of machine learning, so in the case of supervised learning, it is done by extracting features, but in the case of unsupervised learning, the system works to direct the important features and according to priority.

(iii) Easy to assess the accuracy and significance by using mean square error (MSE) and R2

(iv) DNN finds it easy to handle the nonparametric method without prior knowledge for distribution and $\mathrm{I} / \mathrm{O}$ mapping function

(v) Flexibility when dealing with noisy, missing, or incomplete data

(vi) Easy to update according to the changing environment to be dynamic and suitable

7.3. Deep Learning. With the development in data science and modern technology such as big data and high-performance computers, an opportunity for machine learning to understand data and behavior of it through complex systems is provided. Machine learning gives the machine ability to learn in different algorithms without strict orders from certain program or limited instruction [26].

DL can be defined as a technique of machine learning to learn useful features directly from given different media or 


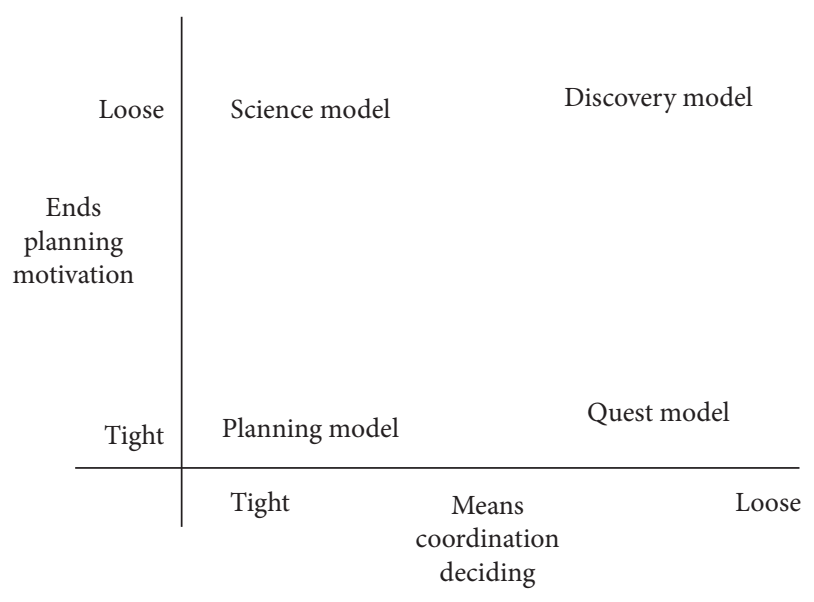

FIgURE 2: Strategies of the management model.

problems. Many layers are exploited by DL for nonlinear data processing of unsupervised or supervised feature extraction for classification and pattern recognition [27]. DL motivation is greatly reduced by artificial intelligence (AI) area, which simulates the ability of the human brain in terms of analyzing, making decision, and learning. Deep learning goal is to emulate approach of hierarchical learning of extracting features by the human brain directly from unsupervised data.

The core of deep learning is the hieratically computed features and representation of information, such as defining of the features starting from the low level to high level. With huge data from the complex management model, the standard techniques' traditional method does not work well when running directly due to the ignoring nature of data behavior. In deep learning, features are extracted automatically from given management models. The characteristics of this method of features considered one of the learning in the system $[28,29]$.

Features as inputs are considered important for successful prediction, and features extracted such financial properties and estimated cost are used in the management model [30]. For this reason, we can use deep learning by its feature extraction to solve limitation in such systems.

The term of DNN in the management model is the understanding of information behavior and draws the strategy, as shown in Figure 4.

Features in deep learning will be generated automatically to simulate the appropriate results [28]. Different hidden layers participate in decision-making by using the feedback from one layer to the previous one or the resulting layer will be fed into the first layer [31]. DL enables computers to be able to perform complex calculations by relying on simpler calculations to optimize computer efficiency. It is difficult for a computer to understand complex data such as collection data from literature or a series of data of a complex nature, so we use deep learning algorithms instead of usual learning methods [32].

Deep learning is considered in this study based on features' extraction and hidden layers of neural network to predict the results. Prediction part is the most important part here.
7.4. Proposed Method. One of the most important features of DNN is the learning process, which is of two types: training mode and testing mode. Deep learning cannot function without input such as the features that is previously extracted. Contributions in previous studies differ on the quality of the features, which determines the accuracy of the results. Most of the existing studies contribute in this issue, and to improve the method, more useful features and maybe with their weights need to be investigated through.

DNN structure in this research includes features extracted with their weights. Features collected in the vector are the same as weights in the input layer while real learning will be in hidden layers, as shown in Figure 5 .

Weight vector $\vec{W}$ is the intermediate vector that controls the main vector of features called $\vec{U}$ which is updated through the manipulated system.

The output layer results will predict the cases in the management model. Many features are extracted from the management model such as time, number of employees, expert of manager duration, structure of institution or company, and economy increases for this year and the previous one. $\mathrm{NN}$ is suitable for prediction; then, most of the results make prediction for certain problem, estimation result can have an effect under certain condition and limitation, and these limitations are considered as weight to the system. Forward propagation process aims to divide the inputs into $n$ vectors of input, and $w$ denotes the weight coefficient and $b$ is known as the bias vector. Vector $x$ denotes the nonlinear operation performance. Function is expressed as

$$
z_{i}=\sum_{i} w_{\text {in }} * x_{n}+b_{i}
$$

where $z_{i}$ is the output of $i$ th layers. The general system using DNN in model management is shown in Figure 6 which illustrates the sequence of the processes in any management model. Any system based on neural network results as prediction and it is limited by the features.

Collection of features is inputted to the system, each with their weights. The proposed method depends mainly on the weight in determining the priority of the features extracted in the process of unsupervised learning, so it is necessary to pay attention to the weight of each feature in the proposed system and effective of each one. $F(u)$ is the function that is responsible for establishing the hidden layer according to the features.

Weights affect the accuracy of system through hidden layers during process. In management, real time is taken as input for some application models, but in normal management, all features are taken in consideration. While running the system, many round processes will be generated as additional hidden layers and many iterations have an effect until they gain appropriate results in terms of accuracy of prediction. Structure of management is necessary for prediction of the results, and any company or project will have priorities in terms of staff hierarchy, as shown in Figure 7.

7.5. Experimental Results. In this study, DNN of the management model is presented in addition to analyses of the strategies of company and institutes. The number of hidden 


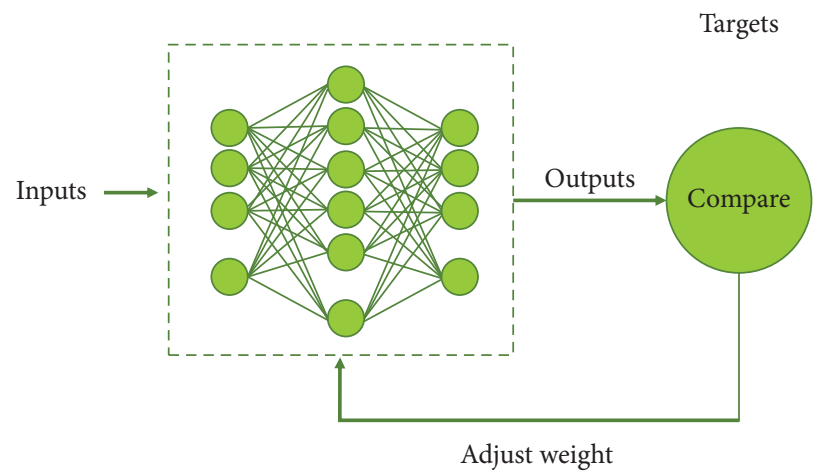

FIgURE 3: Mechanism showing multiple hidden layers with adjusted weight of NN.

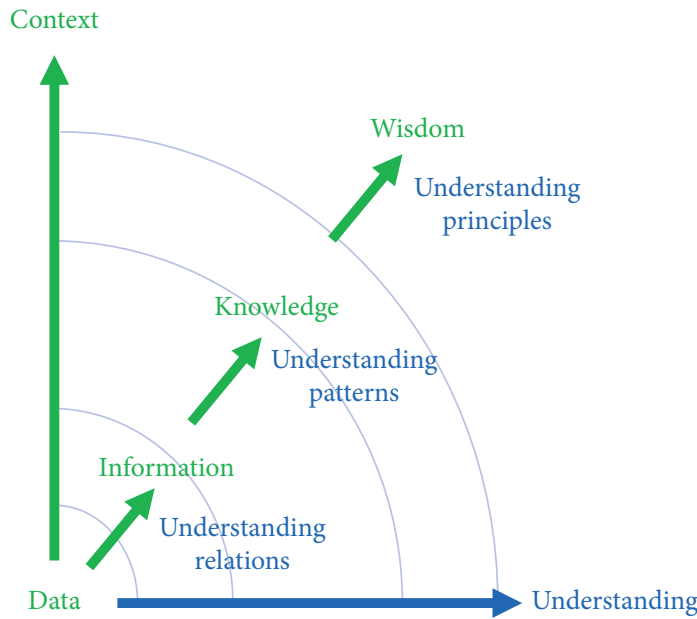

Figure 4: DNN in terms of information strategy.

layers for DNN is used to set the node for each one. Feedforward and backpropagation are performed for neural network. The neural network trains with two main inputs, year and actual consumption, and sets the learning rate with momentum coefficient 0.8 for the process of learning. For good fits, 80,000 iterations are used until satisfying results are obtained. Two main validation parameters are absolute mean relative error (AMRE) and variance $\left(R^{2}\right)$ :

$$
\begin{aligned}
\operatorname{AMRE} & =\frac{1}{n} \sum_{i=1}^{n} \frac{100\left|a_{i}-y_{i}\right|}{a_{i}}, \\
R^{2} & =1-\frac{\sum_{i=1}^{n}\left(a_{i}-y_{i}\right)^{2}}{\sum_{i=1}^{n}\left(y_{i}\right)^{2}},
\end{aligned}
$$

where $a_{i}$ is the actual value, $y_{i}$ is the output value, and $n$ is the data value number. Fitting function performance changed with the number of iterations; the system in the training mode reaches more than usual to get accurate results, as shown in Figure 8.

Six samples of management models have an effect on the fitness function and behave perfectly within the same conditions. The testing mode evaluates the system for these six models. Many evaluation criteria are used to evaluate the system of management models based on DNN, but in the proposed system, three main evaluation tools are used. Fitness function behaves in testing mode shows in Figure 9.

Another two evaluation methods are used with real and standard dataset. Data are obtained from the previous study from different institutes. Propose system based on training and testing modes; testing occurs on real data but should train the system with known results data first so that better results can be achieved. Any system using DNN must label the data from literature studies. AMRE and $R^{2}$ are also used for evaluation in different scopes, as shown in Table 1. 


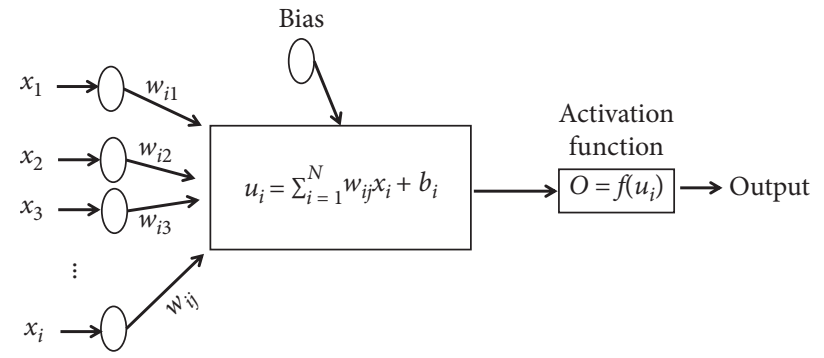

FIgURE 5: Features in DNN of the proposed system.

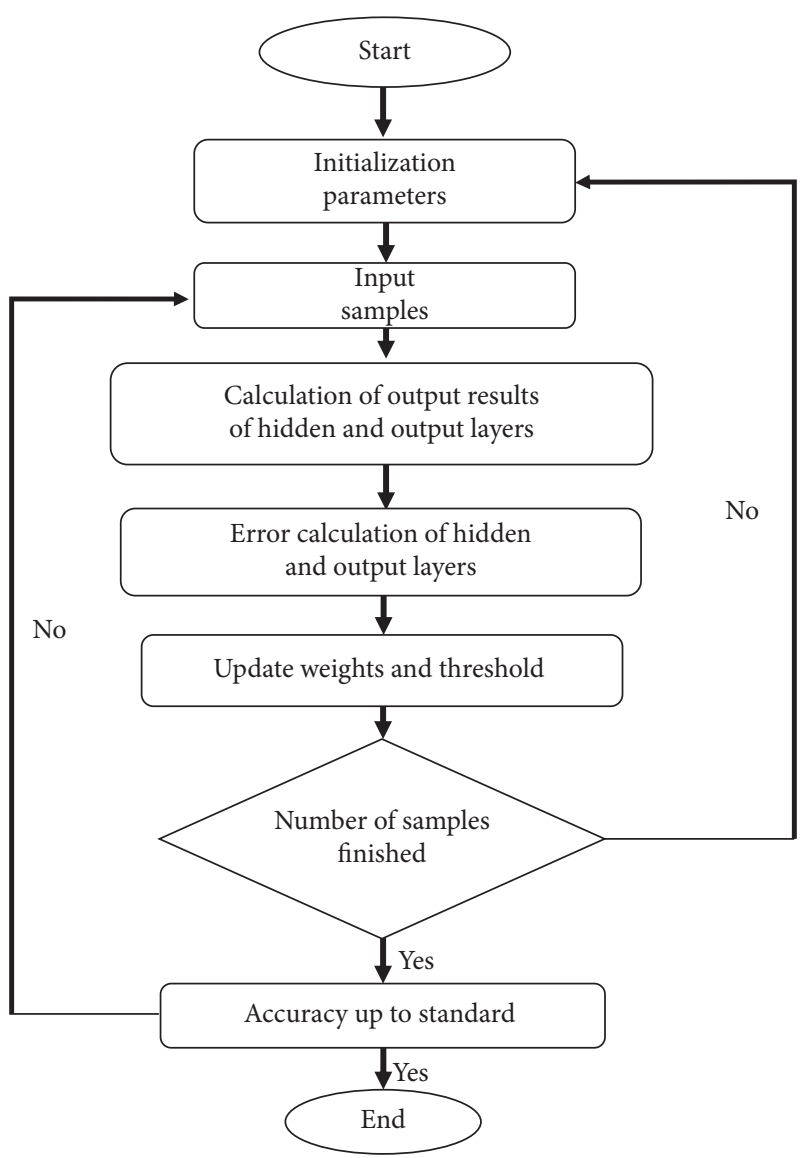

FIGURE 6: General processes within the DNN support management model. 


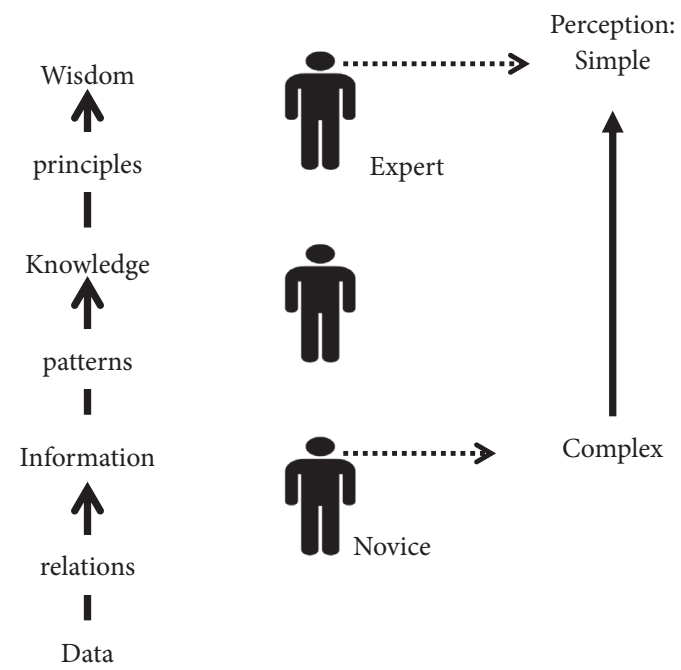

FIgURE 7: Data flow within the management model in DNN.

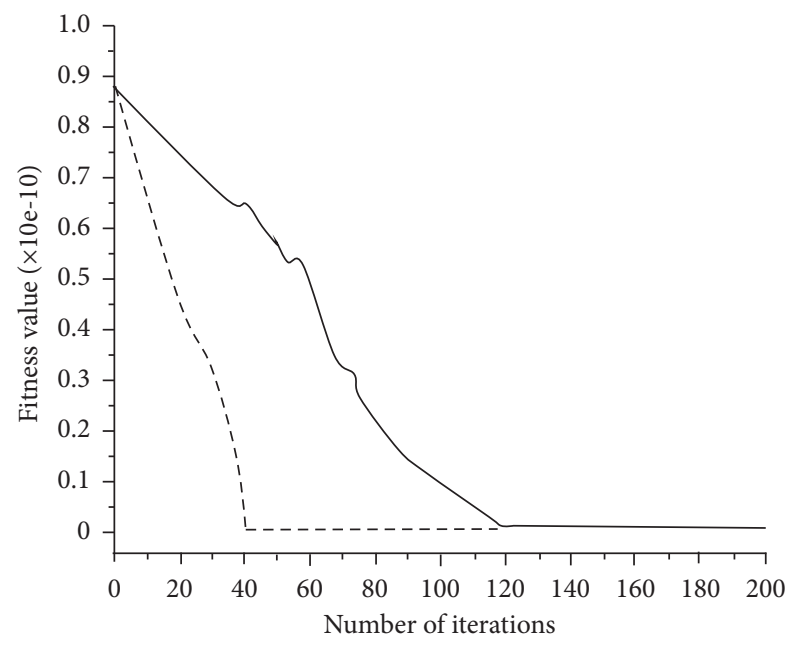

FIGURE 8: Fitness behavior function during number of iterations in the training mode.

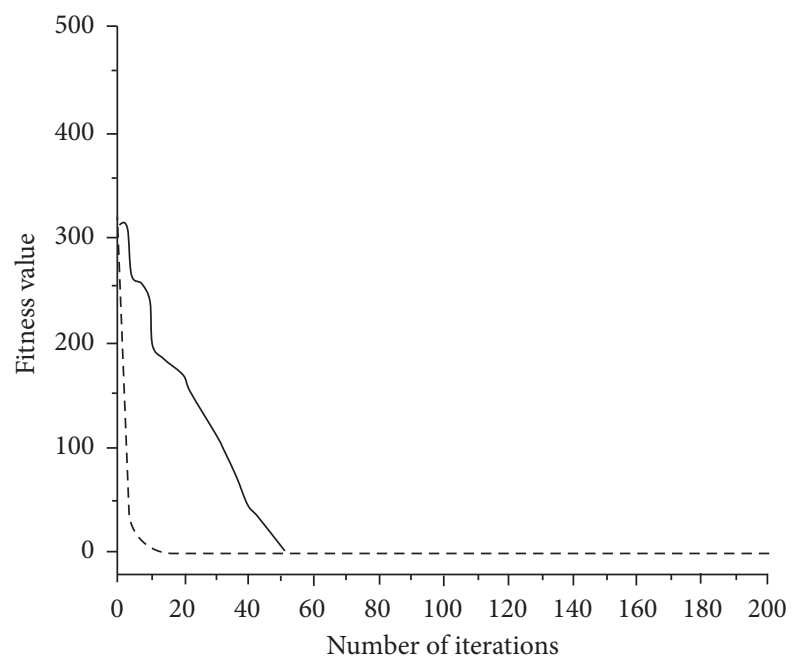

FIGURE 9: Fitness function in the testing mode. 
TABLE 1: Accuracy result of three management models.

\begin{tabular}{lccc}
\hline Evaluation type & Big company & Health issue & Industry \\
\hline Actual & 123 & 145 & 112 \\
DNN & 122 & 144.1 & 111 \\
AMRE & 1.91 & 2.24 & 3.11 \\
R2 & 0.9984 & 0.9965 & 0.999 \\
\hline
\end{tabular}

Good results and high accuracy reflect the worth of the system, and the proposed system achieved acceptable results and can be used for testing other management models.

\section{Conclusion}

The management model is responsible for putting the strategy for organization. Within new technology, modern applications can be used to apply in the management model. $\mathrm{DNN}$ is used to satisfy the management models within updated hidden layers that are based on feedforwarding and backpropagation. Features extracted in advance are taken from informative data of staff employee and manager. Weights derived from the same features and the natural work in management are used in DNN to fulfill the complex calculation of feature function. AMRE and $R^{2}$ are used in the proposed system to evaluate $\mathrm{DNN}$ in the management model in addition to the accuracy of the system. The achieved result was encouraging and recommends the proposed method to be applied in another management project which needs to be predicted based on prior knowledge. For future work, increasing the number of features to extract and using big dataset for prediction are suggested.

\section{Data Availability}

All data used to support the findings of this study are included within the article.

\section{Conflicts of Interest}

The author confirms that there are no conflicts of interest regarding the study of this paper.

\section{Acknowledgments}

The author extends her appreciation to Heilongjiang Province Philosophy and Social Science Fund (19JYE255) for funding and supporting this work.

\section{References}

[1] V. Stavrakas and A. Flamos, "A modular high-resolution demand-side management model to quantify benefits of demand-flexibility in the residential sector," Energy Conversion and Management, vol. 205, p. 112339, 2020.

[2] P. Wang, Z. Zhang, L. Fu, and N. Ran, "Optimal design of home energy management strategy based on refined load model," Energy, vol. 218, p. 119516, 2021.

[3] P. L. S. Steffen, C. S. Mendonça, E. Meyer, and D. D. FaustinoSilva, "Motivational interviewing in the management of type 2 diabetes mellitus and arterial hypertension in primary health care: an RCT," American Journal of Preventive Medicine, vol. 60, pp. e203-e212, 2021.

[4] S. Jiang, H. Shi, W. Lin, and H.-C. Liu, "A large group linguistic Z-DEMATEL approach for identifying key performance indicators in hospital performance management," Applied Soft Computing, vol. 86, p. 105900, 2020.

[5] G. K. Stahl, C. J. Brewster, D. G. Collings, and A. Hajro, "Enhancing the role of human resource management in corporate sustainability and social responsibility: a multistakeholder, multidimensional approach to HRM," Human Resource Management Review, vol. 30, no. 3, p. 100708, 2020.

[6] R. R. Kazaryan and P. I. Andreeva, "Aspects of the system Approach to inventory management," IOP Conference Series: Materials Science and Engineering, IOP Publishing, vol. 753, no. $4,2020$.

[7] P. Gigliotti, "Understanding heterogeneous effects of performance management: an application of kroll's contingency approach to educational accountability," Perspectives on Public Management and Governance, vol. 4, pp. 30-46, 2020.

[8] I. Lizarralde, T. Fernández-Arévalo, A. Manas, E. Ayesa, and P. Grau, "Model-based opti mization of phosphorus management strategies in Sur WWTP, Madrid," Water Research, vol. 153, pp. 39-52, 2019.

[9] A. Zappone, M. Di Renzo, and M. Debbah, "Wireless networks design in the era of deep learning: model-based, AIbased, or both?" IEEE Transactions on Communications, vol. 67, no. 10, pp. 7331-7376, 2019.

[10] D. A. Bashar, "Survey on evolving deep learning neural network architectures," Journal of Artificial Intelligence and Capsule, vol. 2019, no. 2, pp. 73-82, 2019.

[11] P. Büyükbalcı, E. Ertemsir, and Z. Boukari, "Embracing product innovativeness in technology firms: the impact of management model principles," Technology Innovation Management Review, vol. 10, no. 12, 2020.

[12] V. D'Amato and T. Elena, "Does the relationship between manager and employee affect the employees' propensity to recommend their manager?" World journal of management, vol. 11, pp. 17-27, 2020.

[13] L. Batchenko, M. Dielini, and L. Honchar, "A value-oriented polyparadigmal approach to the development of management education in the conditions of transformation change," Baltic Journal of Economic Studies, vol. 6, no. 5, pp. 42-53, 2020.

[14] J. Peterková, K. Czerná, and P. Macurová, "Evaluation of innovation activities and innovation management model of selected innovative companies," SHS Web of Conferences, EDP Sciences, vol. 74, 2020.

[15] I. Kmecová, S. Svobodová, and P. Kaiseršatová, “Zhodnocení manažerských dovedností a kompetencí vysokoškolských studentů," Podnikatelské Kompetence a Řizení Lidských Zdrojů Ve 21. století, p. 64, 2019.

[16] S. Javadinejad, K. Ostad-Ali-Askari, and S. Eslamian, “Application of multi-index decision analysis to management scenarios considering climate change prediction in the Zayandeh Rud River Basin," Water Conservation Science and Engineering, vol. 4, no. 1, pp. 53-70, 2019. 
[17] L. F. Maimó, A. Huretas, M. G. Perez, F. J. G. Clemente, and G. M. Perez, "Dynamic management of a deep learning-based anomaly detection system for 5G networks," Journal of Ambient Intelligence and Humanized Computing, vol. 10, no. 8, pp. 3083-3097, 2019.

[18] L. Zhang, J. Lin, B. Liu, Z. Zhang, X. Yan, and M. Wei, "A review on deep learning applications in prognostics and health management," IEEE Access, vol. 7, pp. 162415-162438, 2019.

[19] M. Cherrington, Z. Lu, Q. Xu, D. Airehrour, S. Madanian, and A. Dyrkacz, "Deep learning decision support for sustainable asset management," Advances in Asset Management and Condition Monitoring, Springer, Cham, New York, NY, USA, pp. 537-547, 2020.

[20] T. J. Sheng, M. S. Islam, N. Misran et al., "An internet of things based smart waste management system using LoRa and tensorflow deep learning model," IEEE Access, vol. 8, pp. 148793-148811, 2020.

[21] M. Anbarasan, B. Muthu, C. B. Sivaparthipan et al., "Detection of flood disaster system based on IoT, big data and convolutional deep neural network," Computer Communications, vol. 150, pp. 150-157, 2020.

[22] A. S. M. Alharbi and E. de Doncker, "Twitter sentiment analysis with a deep neural network: an enhanced approach using user behavioral information," Cognitive Systems Research, vol. 54, pp. 50-61, 2019.

[23] J. Duan, "Financial system modeling using deep neural networks (DNNs) for effective risk assessment and prediction," Journal of the Franklin Institute, vol. 356, no. 8, pp. 4716-4731, 2019.

[24] A. Essien and C. Giannetti, “A deep learning model for smart manufacturing using convolutional LSTM neural network autoencoders," IEEE Transactions on Industrial Informatics, vol. 16, no. 9, pp. 6069-6078, 2020.

[25] H. Jahangir, H. Tayarani, S. Baghali et al., "A novel electricity price forecasting approach based on dimension reduction strategy and rough artificial neural networks," IEEE Transactions on Industrial Informatics, vol. 16, no. 4, pp. 2369-2381, 2019.

[26] M. de Prado Lopez, Advances in Financial Machine Learning, John Wiley and Sons, Hoboken, NJ, USA, 2018.

[27] G. Sulong and A. Mohammedali, "Human activities recognition via features extraction from skeleton," Journal of Theoretical and Applied Information Technology, vol. 68, no. 3, pp. 645-650, 2014.

[28] E. Hassan, Y. Khalil, and I. Ahmad, "Learning feature fusion in deep learning-based object detector," Journal of Engineering, vol. 2020, Article ID 7286187, 11 pages, 2020.

[29] G. Sulong and A. Mohammedali, "Recognition of human activities from still image using novel classifier," Journal of Theoretical and Applied Information Technology, vol. 71, no. 1, pp. 151-121, 2015.

[30] A. Rosato, M. Panella, R. Araneo, and A. Andreotti, "A neural network based prediction system of distributed generation for the management of microgrids," IEEE Transactions on Industry Applications, vol. 55, no. 6, pp. 7092-7102, 2019.

[31] B. T. Atiyha, S. Aljabbar, A. Ali, and A. Jaber, "An improved cost estimation for unit commitment using back propagation algorithm," Malaysian Journal of Fundamental and Applied Sciences, vol. 15, no. 2, pp. 243-248, 2019.

[32] D. Xie, L. Zhang, and L. Bai, "Deep learning in visual computing and signal processing," Applied Computational Intelligence and Soft Computing, vol. 2017, Article ID 1320780, 13 pages, 2017. 